\title{
Whole-body-hyperthermia-induced Changes Interstitial Collagenase Activity and an Extracellular Matrix Remodeling Theory
}

\author{
AKIRA TAKEUCHI*, HIROMI HASUMURA, MICHIAKI SEKIYA, \\ MASAKAZU SHIRAHIGE, EMI HARAYAMA, SACHIKO KOTOYORI, \\ TAKASHI TAKEUCHI
}

Department of Thermotherapy, Luke Clinic, 3-6-1 Nogata Nakano-ku, Tokyo 165-1127, Japan

\begin{abstract}
Matrix metalloproteinase-1 (MMP-1) has received a considerable attention as one of factors, enhancing tumor infiltration and metastasis. We determined serum levels of MMP-1 and TIMP-2, a tissue inhibitor of metalloproteinase-2 (a protein that suppresses all MMPs activity). Furthermore, we monitored changes in serum levels of MMP-1 and TIMP-2 after Whole Body Hyperthermia (WBH). Samples were collected from 46 patients with advanced cancers and 20 healthy volunteers were also examined for MMP-1 and TIMP-2. Furthermore, they were monitored for 36 patients undergoing one cycle of WBH, three weeks after completion of WBH. Mean serum level of MMP-1 in patients was increased to a significant extent whereas mean serum level of TIMP-2 was markedly lowered, compared to healthy individuals. MMP-1 activity was assessed by MMP-1/TIMP-2 ratio, and the ratio was 0.43 for cancer patients and 0.15 for healthy individuals, thus showing that cancer patients exhibited an apparently higher MMP-1/TIMP-2 ratio than healthy individuals. MMP-1 activity was nearly normalized in 9 responders after WBH, i.e., from 0.37 (before) to 0.21 (after), whereas MMP-1 activity was increased from 0.43 (before) to 0.51 (after) in 27 non-responders. MMP-1 activity was increased approximately by 3 -fold in patients, compared to healthy individuals. MMP-1 activity was normalized in WBH-responders.
\end{abstract}

Key Words : metastasis, whole body hyperthermia, MMP, collagen

\section{Introduction}

A number of preclinical studies ${ }^{1,2)}$ have demonstrated that cancer cells induce lysis of extracellular matrix (ECM) via secretion of matrix metalloproteinase (MMP), leading to invasion of tumor cells to surrounding tissues and metastasis to distant organs. Among a variety of matrix metalloproteinases reported thus far, MMP-1 is responsible for digesting type I, II and III collagen molecules, the main constituents of ECM. In spite of its vital roles in tumor metastasis, MMP-1 activities have not been assessed thoroughly in cancer patients, using serum samples as a routine clinical test. In the present

Received 27 August, 2010, Accepted 2 December, 2010. *Corresponding author ; Tel, +81-3-5345-7281 ; Fax, 81-3-5345-7282; 
Thermal Med, 26 [4] : 109-119, 2010.

study, we determined serum levels of MMP-1 and tissue inhibitor of metalloproteinase-2 (TIMP-2), one of inhibitors of MMP-1, and assessed blood levels of MMP-1 activities, namely, systemic interstitial collagenase activities in tumor-bearing patients who have been treated on an outpatient basis at the whole body hyperthermia (WBH) clinic. Furthermore, we examined WBH-induced changes in MMP-1 activities and evaluated inhibitory effects of WBH on tumor metastasis and infiltration. In addition, we have proposed a theory for heat-induced lysis of interstitial collagen matrix and discussed our results, based on this theory.

\section{Materials and methods}

\section{Subjects}

Blood samples were collected at the time of initial visit from a total of 46 patients with advanced cancers (as defined by the NCI classification) (including 23 men and 23 women with a mean age of 57.6 years) who visited Department of Thermotherapy, Luke Hospital between May 1998 and January 1999. All of them had relapsed metastatic cancer excluding two patients. As a control, 20 healthy volunteers (including 10 men and 10 women with a mean age of 29.5 years) were examined for serum levels of MMP-1 and TIMP-2. Furthermore, serum levels of MMP-1 and TIMP-2 were monitored for 36 patients undergoing $\mathrm{WBH}$ (once weekly, a total of 4 cycles) (including 18 men and 18 women with a mean age of 55.5 years) at completion of one cycle of WBH as well as 2 and 3 weeks after initiation of WBH.

In addition, we determined serum levels of 1-CTP before and immediately after induction of hyperthermia at $41.5^{\circ} \mathrm{C}$, as well as $3 \mathrm{~h}$ and one week after induction of hyperthermia at $41.5^{\circ} \mathrm{C}$ in 12 patients without bone metastasis.

\section{Method}

Immediately after collection of blood samples from patients with advanced cancer, serum was separated by centrifugation and serum levels of MMP-1, TIMP-2 and 1-CTP were determined at Mitsubishi Kagaku Bio-clinical Laboratories, Inc., by the first-step sandwich EIA method (Fuji Chemical Industries, Ltd., Tokyo, Japan) using monoclonal antibodies raised against MMP-1, TIMP-2 and 1-CTP. Similarly, serum samples collected from healthy volunteers were analyzed for MMP-1 and TIMP-2 at the Mitsubishi Kagaku Bio-clinical Laboratories, Inc. in collaboration with this company.

\section{Therapy}

WBH was induced by extracorporeal far-infrared irradiation as proposed by Robins et al. ${ }^{3)}$, using an instrument "RHD2002 and RHS7500 (Enthermics medical systems Inc., WI, US)". Patients with advanced cancer were anesthetized via intravenous administration of anesthetic at a sedative dose that allowed noninvasively to achieve hyperthermia via heating the superficial blood flow, and hyperthermia was induced by maintaining a temperature of $42^{\circ} \mathrm{C}$ locally and $41.0-41.8^{\circ} \mathrm{C}$ systemically (the rectal temperature) for one hour by the use of this instrument. Chemotherapeutic agents were intravenously administered concomitantly while maintaining the rectal temperature at $41^{\circ} \mathrm{C}$ or higher as well as an intense feeling of heat. WBH was indicated for patients with advanced cancer who failed to respond to other conventional chemotherapy but who were able to go home after resting for several hours following 
WBH, i.e. Performance Status of 2 or better without any problems in pulmonary and cardiac functions, in accordance with the inclusion criteria established by Enthermics medical systems. In addition, all our treatments were performed with sufficient informed consent and approval by the ethical committee of the hospital.

\section{Results}

Primary lesions in 50 outpatients with advanced cancers are listed in Table I. At the time of initial visit at the hyperthermia unit of this hospital, mean serum levels of MMP-1 were $19.95 \mathrm{ng} / \mathrm{ml}$ (with standard deviation of 28.0) for cancer patients and $10.52 \mathrm{ng} / \mathrm{ml}$ (with standard deviation of 5.35) for healthy individuals, thus demonstrating that serum levels of MMP-1 were elevated to a significant extent in cancer patients $(\mathrm{P}<0.05$, Student t-test $)$ as shown in Fig. 1. In contrast, mean serum levels of TIMP-2 were $49.20 \mathrm{ng} / \mathrm{ml}$ (with standard deviation of 22.21) for cancer patients and $74.13 \mathrm{ng} / \mathrm{ml}$ (with standard deviation of 16.04) for healthy individuals, thus demonstrating that serum levels of TIMP-2 were lowered to a significant extent in cancer patients $(\mathrm{P}<0.0002)$ as shown in Fig. 2. To make a final assessment of

Table I. Primary lesions in 46 patients with advanced cancer

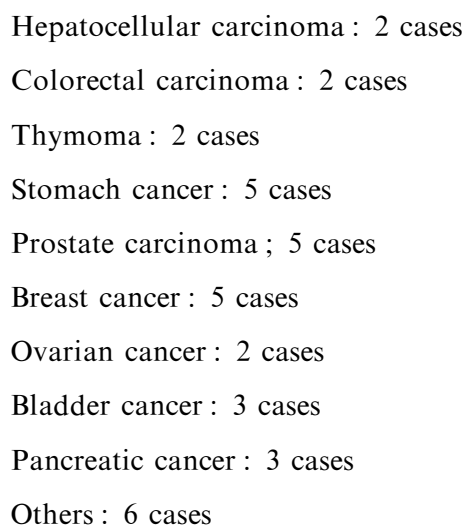

(A total of 44 patients had metastasis.)

Fig. 1. MMP-1 concentration in serum. Mean MMP-1 levels were $19.95 \mathrm{ng} / \mathrm{ml}(\mathrm{N}=50)$ for patients with advanced cancer and $10.52 \mathrm{ng} / \mathrm{ml}(\mathrm{N}=20)$ for healthy individuals, thus showing a significantly higher serum level of MMP-1 for patients with advanced cancer, compared to healthy individuals ( $\mathrm{P}$ value $<0.05$ ).

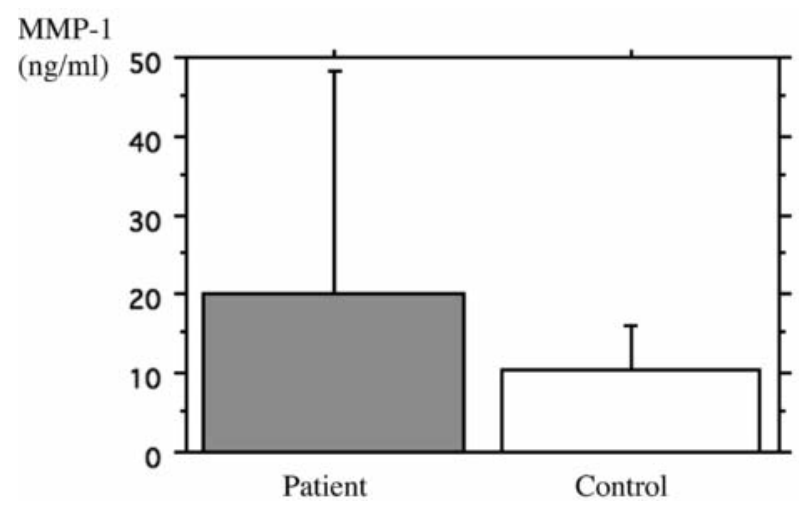


Thermal Med, 26 [4] : 109-119, 2010.

MMP-1 activity, MMP-1/TIMP-2 ratio was determined. As shown in Fig. 3, MMP-1/TIMP-2 ratio was 0.43 (with standard deviation of 0.40) for cancer patients and 0.15 (with standard deviation of 0.096) for healthy individuals, thus revealing significantly higher MMP-1 activities for cancer patients $(\mathrm{P}<0.007)$ than those for healthy volunteers.

Moreover, 36 patients with advanced cancer underwent WBH, and serum levels of MMP-1 and TIMP-2 were re-assessed at week 3 after undergoing WBH. A total of 36 patients were grouped into two in accordance with the UICC Criteria, responders [CR (complete response) and PR (partial response)] ( 9 cases) and non-responders [NC (no change) and PD (progressive disease) ] (27 cases), and serum levels of MMP-1 and TIMP-2 were compared before and after WBH (Table II).

TIMP-2

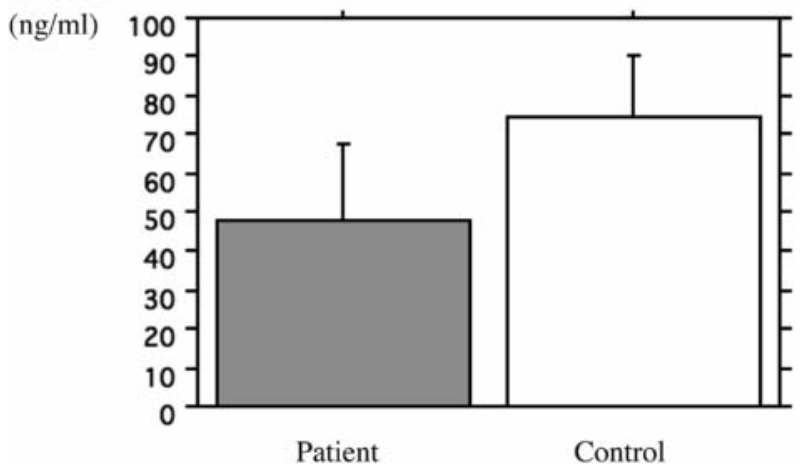

Fig. 2. TIMP-2 concentration in serum. Mean TIMP-2 levels were $49.20 \mathrm{ng} / \mathrm{ml}(\mathrm{N}=50)$ for patients with advanced cancer and $74.13 \mathrm{ng} / \mathrm{ml}(\mathrm{N}=20)$ for healthy individuals, thus showing a significantly lower serum level of TIMP-2 for patients with advanced cancer, compared to healthy individuals ( $\mathrm{P}$ value $<0.0002$ ).
MMP-1/TIMP-2

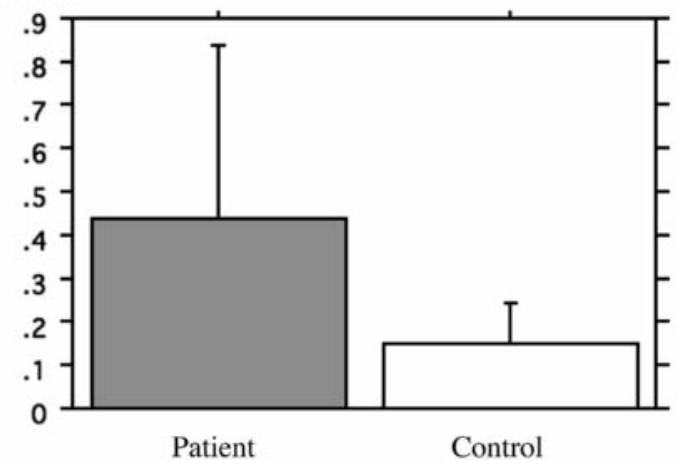

Fig. 3. MMP-1/TIMP-2 ratio in serum. Serum MMP-1/TIMP-2 ratio was $0.43(\mathrm{~N}=50)$ for patients with advanced cancer and $0.15(\mathrm{~N}=20)$ for healthy individuals, thus showing a significantly higher serum MMP-1/TIMP-2 ratio for patients with advanced cancer, compared to healthy individuals ( $\mathrm{P}$ value $<0.007$ ).

Table II. Primary lesions in 36 cancer patients treated with WBH

\author{
Responders (3 cases with $\mathrm{CR}+6$ cases with PR) \\ Non small cell carcinoma of the lung: 3 cases \\ Breast cancer : 2 cases \\ Hepatocellular carcinoma : one case \\ Thymoma : one case \\ Stomach cancer: one case \\ Pancreatic cancer: one case \\ Non-responders (10 cases with $\mathrm{NC}+17$ cases with $\mathrm{PD}$ ) \\ Non small cell carcinoma of the lung: 5 cases \\ Hepatocellular carcinoma : one case \\ Colon cancer : 6 cases \\ Thymoma : one case \\ Breast cancer: 2 cases \\ Pancreatic cancer : one case \\ Ovarian cancer : 2 cases \\ Stomach cancer : one case \\ Pancreatic cancer : one case \\ Others : 7 cases
}


Serum levels of MMP-1 in responders were $15.46 \mathrm{ng} / \mathrm{ml}$ (with standard deviation of 4.51 ) before WBH and $9.58 \mathrm{ng} / \mathrm{ml}$ (with standard deviation of 2.70) after WBH, thus showing a significant decrease in serum MMP-1 level after WBH $(\mathrm{P}<0.02)$. As a matter of fact, serum MMP-1 level declined to a normal level after WBH. In contrast, serum levels of MMP-1 in non-responders were $21.09 \mathrm{ng} / \mathrm{ml}$ (with standard deviation of 6.93) before WBH and $27.63 \mathrm{ng} / \mathrm{ml}$ (with standard deviation of 10.63) after WBH, thus revealing a trend that serum levels of MMP-1 were rather elevated after WBH, as shown in Fig. 4.

In addition, there were no significant changes in serum levels of TIMP-2 before and after WBH, as shown in Fig. 5. However, MMP-1/TIMP-2 ratio declined from 0.37 (before WBH, with standard deviation of 0.12 ) to 0.21 (after WBH, with standard deviation of 0.05 ) among responders, indicating that MMP-1 activity was suppressed to a normal level. In contrast, MMP-1/TIMP-2 ratio increased from 0.43 (before WBH, with standard deviation of 0.08) to 0.51 (after WBH, with standard deviation of 0.08) among non-responders, indicating that MMP-1 activity was rather enhanced in non-responders as shown in Fig. 6.

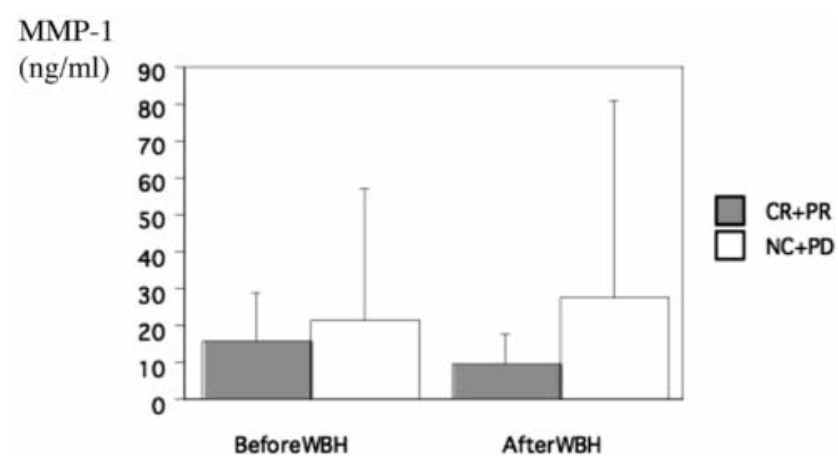

Fig. 4. Changes in serum MMP-1 concentration before and after treatment with WBH. In responders, mean MMP-1 concentration dropped from 15.46 $\mathrm{ng} / \mathrm{ml}$ to $9.58 \mathrm{ng} / \mathrm{ml}(\mathrm{N}=9)$ after treatment with WBH $(\mathrm{P}<0.02)$. To the contrary, mean MMP-1 concentration was increased from $21.09 \mathrm{ng} / \mathrm{ml}$ to $27.63 \mathrm{ng} / \mathrm{ml} \quad(\mathrm{N}=27)$ in non-responders, after treatment with WBH.

TIMP-2

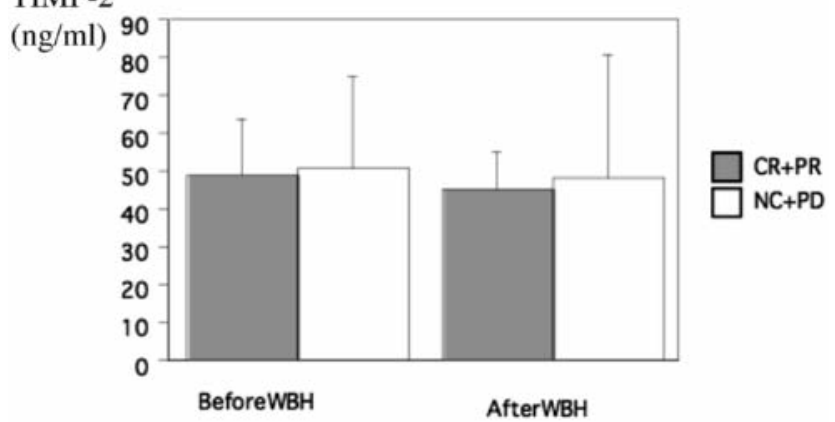

Fig. 5. Changes in serum TIMP-2 concentration before and after treatment with WBH. No change in serum TIMP-2 concentration was noted for responders and non-responders, before and after treatment with WBH.

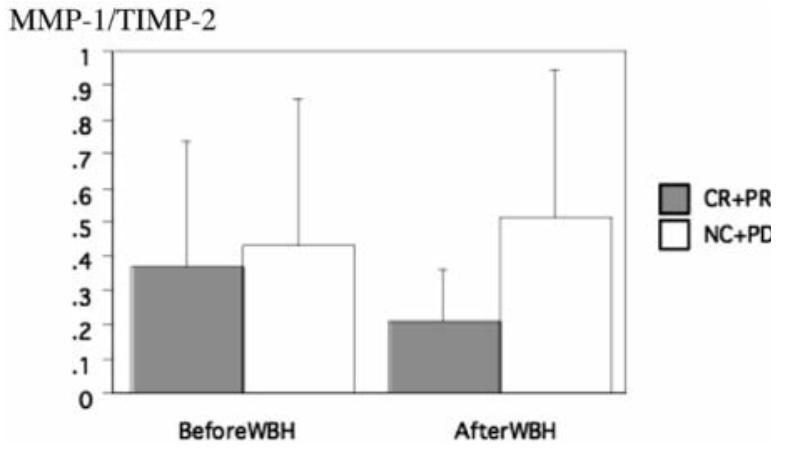

Fig. 6. MMP-1/TIMP-2 ratio in serum. In responders, MMP-1/TIMP-2 ratio dropped from 0.37 to $0.21 \quad(\mathrm{~N}=9)$ after treatment with WBH. In non-responders, MMP-1/TIMP-2 ratio was rather increased from 0.43 to $0.51(\mathrm{~N}=27)$. 
Thermal Med, 26 [4] : 109-119, 2010.

The serum level of 1-CTP obviously increased transiently at $41.5^{\circ} \mathrm{C}$ as shown in Fig. 7 .

Fig. 7. Changes in blood levels of I-CTP after treatment with whole body hyperthermia (WBH). Mean levels of I-CTP were $5.5 \mathrm{ng} / \mathrm{ml}$ $(\mathrm{N}=7)$ before $\mathrm{WBH}$ and $10.5 \mathrm{ng} / \mathrm{ml}$ after $\mathrm{WBH}$ by maintaining the rectal temperature of $41.5^{\circ} \mathrm{C}$ systemically for $60 \mathrm{~min}$, showing a significant rise in blood levels of I-CTP after WBH $(\mathrm{P}<$ 0.012). Mean levels of I-CTP dropped to 7.6 $\mathrm{ng} / \mathrm{ml}$ at $3 \mathrm{~h}$ after completion of $\mathrm{WBH}$, but remained at $7.0 \mathrm{ng} / \mathrm{ml}$ one week after completion of $\mathrm{WBH}$, showing a slight elevation of blood levels of I-CTP as compared with pretreatment levels $(\mathrm{P}$ value $<0.03)$.

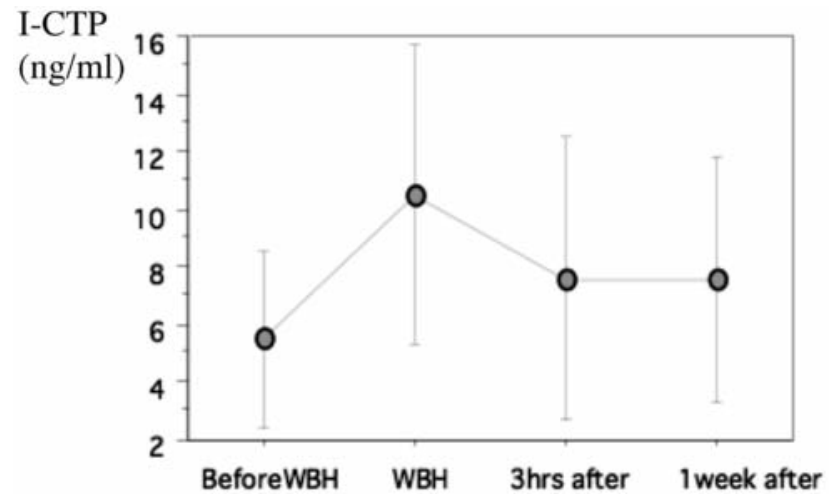

Cases

Case No. 1 underwent two cycles of $\mathrm{WBH}$ and responded to this therapy, and the results were reproducible. The patient was a female who developed pleural metastasis after undergoing thymectomy (primary lesion: malignant thymoma). As shown in Fig. 8, a striking reduction in pleural tumor size was noted after completion of each cycle of $\mathrm{WBH}$, and serum levels of tumor markers and MMP-1 were decreased.

Case No. 2 developed pleural metastasis after undergoing surgery for adenocarcinoma of the lung, as shown in Fig. 9. Although no obvious reduction in tumor size has been noted, chest pain was markedly alleviated, and serum levels of tumor markers and MMP-1 were normalized after undergoing WBH. These two patients were concomitantly treated with low-dose chemotherapy.

Case No. 3 with hepatocellular carcinoma was treated with $\mathrm{WBH}$
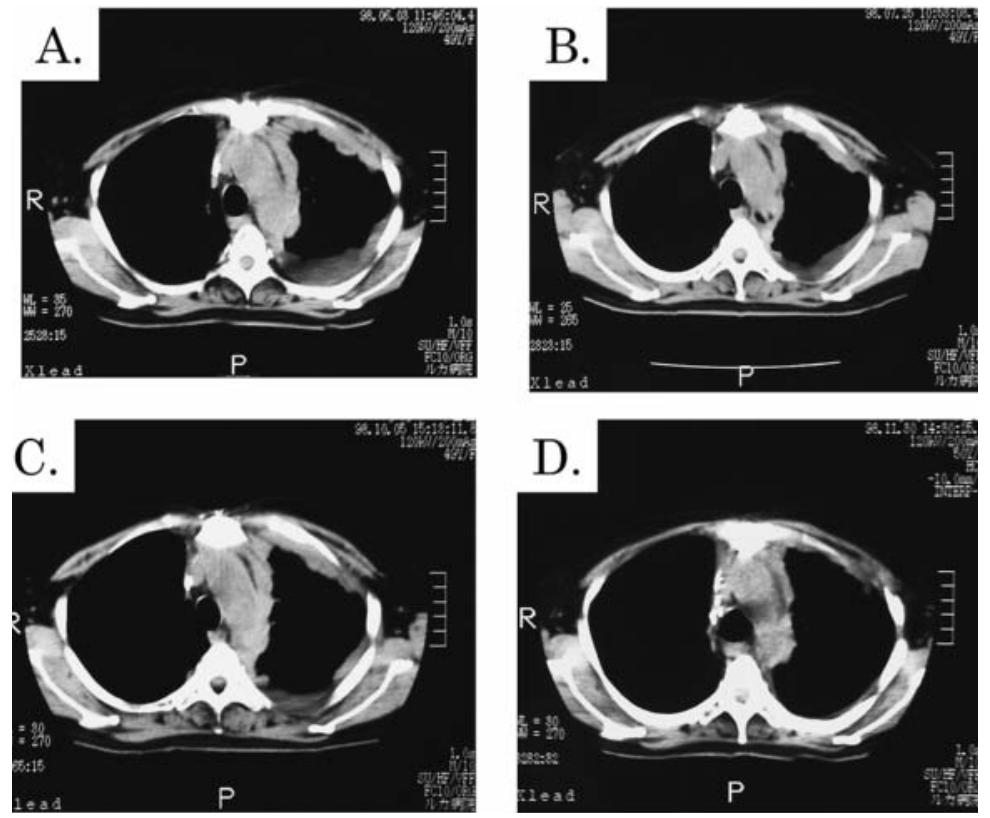

Fig. 8. Case No. 1 with malignant pleural tumor. Changes in serum levels of MMP-1 and TIMP-2 after WBH. Panel A: On June 3, 1998 prior to the first $\mathrm{WBH}$, pleura was markedly thickened on CT due to left pleural tumor. The patient complained of pain on the back and dyspnea. Serum MMP-1 level $=7.28 \mathrm{ng} / \mathrm{ml}$, serum TIMP-2 level $=33.7 \mathrm{ng} / \mathrm{ml}$, MMP-1 $/$ TIMP-2 ratio $=0.216$ (prior to $\mathrm{WBH}$ ). Panel B : On July 25, 1998 (two weeks after the first WBH), pleural tumor shrank in size on CT. Pain on the back and dyspnea were alleviated. Serum MMP-1 level $=3.62 \mathrm{ng} / \mathrm{ml}$, serum TIMP-2 level $=44.2 \mathrm{ng} / \mathrm{ml}$, MMP-1/TIMP-2 ratio $=0.082$. Panel $\mathrm{C}:$ On October 5, 1998 (prior to the second WBH), there was a sign indicating relapse of pleural tumor on CT. Serum MMP-1 level= $6.38 \mathrm{ng} / \mathrm{ml}$, serum TIMP-2 level $=68.5 \mathrm{ng} / \mathrm{ml}$, MMP-1 $/$ TIMP-2 ratio $=0.093$. Panel D : On November 30, 1998 (two weeks after the second $\mathrm{WBH}$ ), the pleural lesion nearly disappeared on CT and the patient no longer complained of pain on the back and dyspnea. Serum MMP-1 level $=1.00 \mathrm{ng} / \mathrm{ml}$, serum TIMP-2 level $=56.2 \mathrm{ng} /$ ml, MMP-1/TIMP-2 ratio $=0.018$. 
alone. As shown in Fig. 10, the primary lesion became necrotic and serum level of MMP-1 was normalized, accompanied by improvements in AFP. Thus, serum level of MMP-1 level was decreased, whether treated with WBH alone or in combination with chemotherapy.
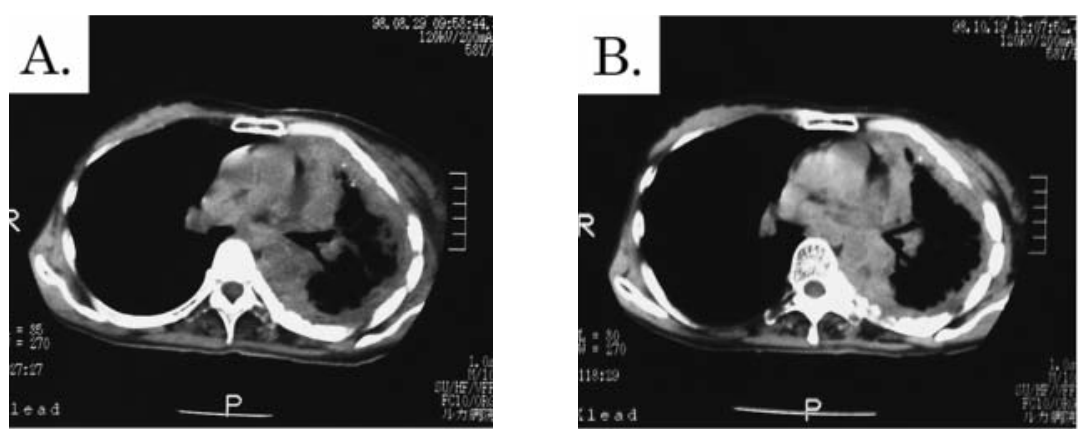

Fig. 9. Case No. 2 (A patient with adenocarcinoma of the lung metastasis to pleura). Changes in serum levels of MMP-1 and TIMP-2 after WBH. Panel A: On August 3, 1998 prior to the first WBH, pleura was markedly thickened on CT due to the left pleural metastasis. The patient complained of pain on the back and dyspnea. Serum MMP-1 level $=45 \mathrm{ng} / \mathrm{ml}$, serum TIMP-2 level $=59.3 \mathrm{ng} / \mathrm{ml}$, MMP-1/TIMP-2 ratio $=0.759$. Panel B : On July 25, 1998 (two weeks after undergoing WBH), there was almost no change in the left pleural lesion on CT, but pain on the back and dyspnea were markedly alleviated. Serum MMP-1 level $=24.1 \mathrm{ng} / \mathrm{ml}$, serum TIMP-2 level $=49.7 \mathrm{ng} / \mathrm{ml}$, MMP-1 $/$ TIMP-2 ratio $=0.485$.
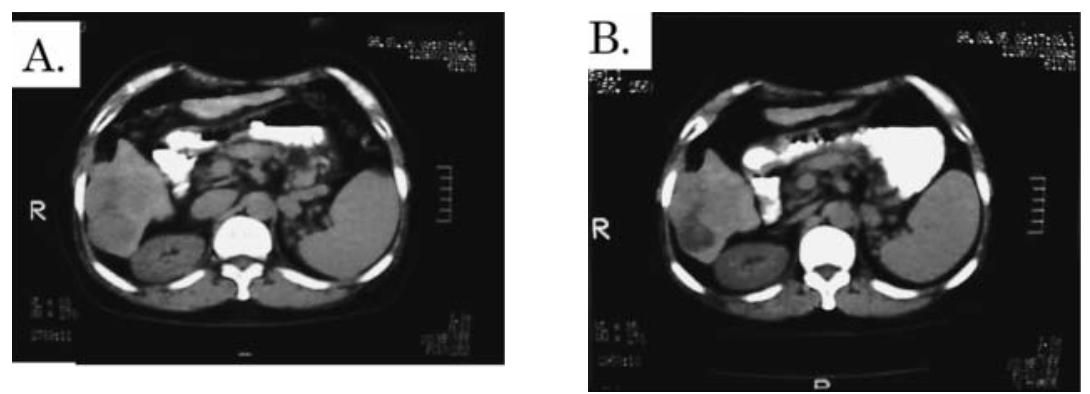

Fig. 10. Case No. 3 (A patient with hepatocellular carcinoma). Changes in serum levels of MMP-1 and TIMP-2 after WBH. Panel A : On May 12, 1998 (prior to WBH), a tumor was found in the right hepatic lobe on CT. The patient complained of right abdominal pain. Serum MMP-1 level=7.92 ng $/ \mathrm{ml}$, serum TIMP-2 level $=64.9 \mathrm{ng} / \mathrm{ml}$, MMP-1/TIMP-2 ratio $=0.122$. Panel B : On June 24, 1998 (two weeks after undergoing WBH), CT revealed necrosis in the hepatic tumor lesion. Right abdominal pain was alleviated. Serum MMP-1 level $=3.83 \mathrm{ng} / \mathrm{ml}$, serum TIMP-2 level $=42.6 \mathrm{ng} / \mathrm{ml}$, MMP- 1 / TIMP-2 ratio $=0.090$. 


\section{Discussion}

Recently, "tumor dormancy therapy: balanced proliferation and apoptosis in the presence of angiogenesis suppression" has been advocated by Folkman et al.4) as a new concept of the treatment for cancer. In other words, "tumor dormancy therapy" has been proposed to achieve a long-term survival via inhibition of tumor growth and metastasis in the presence of neovascularization suppression. It is well-known that a new type of anticancer agents have been under development, based on the control of environmental factors of cancer such as suppression of neovascularization and inhibition of the MMPs activity mentioned above.

First, cancer cells degenerate the basement membrane that made of the type IV collagen, secondly, they deganerate the interstitial collagen, to matastasize.

Recently, it was made public that in the process of metastasis, the type IV callagenase (MMP-2 and MMP-9) is activated by the expression of Membrane type-1 matrix metalloproteinase (MT1-MMP) in cancer cells. Unlike MT1-MMP, a number of investigators ${ }^{5,6)}$ have reported that other matrix metalloproteinases, including MMP-1, are expressed primarily in interstitial cells such as fibroblasts rather than cancer cells.

Murray and associates ${ }^{7)}$ have reported that MMP-1 is associated with poor prognosis in patients with colorectal cancer and that expression of MMP-1 is an independent prognostic factor for colorectal cancer.

Zucker and associates ${ }^{8)}$ determined serum levels of MMP-9 and reported that MMP-9 was increased in plasma of patients with breast cancer and intestinal cancer, in particular, as compared with healthy individuals.

Grigioni and associates ${ }^{9)}$ have reported that MMP-2 expression in gastric cancer tissues correlated with clinical stage of gastric cancer, while TIMP-2 expression in gastric cancer tissues inversely correlated with clinical stage of the disease, as was the case for our study.

The MMP activity has been assessed by MMP/TIMP ratio. Since MMP activity is inhibited by TIMP at a molar ratio of $1: 1$, this method seems to be reasonable. However, MMP/TIMP ratio should always be kept constant in vivo, and it is highly unlikely that MMP/TIMP ratio is unbalanced in serum of healthy individuals, as seen in our present study. It is of great interest to note that serum level of MMP-1 was increased in almost all patients with systemic metastasis.

We have performed WBH using infrared irradiation more than 5,700 times in more than 1,200 patients with advanced cancer since 1991 and reported that improvements in the survival period and QOL were more notable than suppression of the tumor size ${ }^{10)}$. Moreover, we have frequently witnessed rapid healing of bed-sore and improvements in pulmonary fibrosis in patients undergoing WBH. Based on our experiences with WBH using infrared irradiation, we have paid attention to reactions of interstitial tissues induced by hyperthermia.

\section{Remodeling theory in collagen}

As a new hyperthermia theory, we would like to propose a hypothesis "antitumor effect of hyperthermia is mediated through impairment of interstitial tissues induced by heat-degeneration of collagen".

Serum level of 1-CTP (type 1 collagen cross-linked carboxyterminal telopeptide), one of the 
degradation products of type I collagen (interstitial collagen), has been known to rise specifically in patients with osteoporosis or bone metastasis ${ }^{11)}$. In almost all cancer patients undergoing WBH, we have also noted a rapid rise of serum 1-CTP level immediately after inducing WBH. Since this phenomenon is not associated with any other metabolic changes indicating bone resorption, there is a possibility that an increase in serum 1-CTP level alone may account for degradation of type 1 collagen in connective tissues other than bones.

To prove this theory, we assayed the change in serum level of 1-CTP before and after of WBH, as well as $3 \mathrm{~h}$ and one week after. The serum level of 1-CTP obviously increased transiently at $41.5^{\circ} \mathrm{C}$. Moreover, a similar "escape phenomenon" has been observed when type I collagen gel (Cellmatrix type 1-A, Nitta Gelatin Strain that has been widely used for cell culture) was simply heated.

Based on this discovery, we are currently pursuing this approach from the standpoint of "hyperthermia is an interstitial collagen dissolution therapy".

Collagen is the main protein (comprising over half of that in animals) of the white fibers of connective tissue, cartilage, skin and bone, and it has a long half-life (turnover) in vivo. It is heat-stable and a cross-linking structure is formed gradually. However, it is well-known that newly-synthesized collagen molecules undergo a structural alteration of the protein if human collagen is heated at $40^{\circ} \mathrm{C}$ or higher. In animals, collagen undergoes degeneration at a temperature approximately $3-4^{\circ} \mathrm{C}$ higher than that in their living environment, and it is rapidly digested by a variety of proteases ${ }^{12,13)}$, leading to an important cascade pathway for inflammation and wound healing in animals.

Thus, there is a sufficient evidence to support a hypothesis that "collagen that has not acquired heat-stability, namely, only cross-linking structure of newly-synthesized collagen present in immature stromal component of tumor lesion or at the wound site may be impaired by hyperthermia".

In the present study, we have demonstrated significant correlations between changes in serum MMP-1 levels and clinical response to $\mathrm{WBH}$, indicating that hyperthermia exerts cytotoxic effect directly on cancer cells. In addition to direct cytotoxicity, hyperthermia induces degeneration of collagen fibers in tumor lesions via impairment of stromal elements of tumor tissues, eventually resulting in remodeling of extracellular matrix and accounting for serum levels of MMP-1 in responders and non-responders.

Recently, Bull and associates ${ }^{14-16)}$ examined antitumor effect and induction of apoptosis and necrosis after treatment with long-duration, mild whole body hyperthermia $\left(40^{\circ} \mathrm{C}\right.$ for $\left.6 \mathrm{~h}\right)$ in simultaneous combination with a chemotherapeutic agent, cisplatin, on primary and metastatic tumor growth in a rat mammary adenocarcinoma, and reported interesting results. A significantly greater delay in primary mammary tumor growth was observed after treatment with cisplatin, compared to WBH alone. In contrast, WBH alone caused a significant delay in spontaneous metastasis to the axillary lymph node, as compared to cisplatin alone. Furthermore, Ito and associates ${ }^{17)}$ have demonstrated that heat shock suppresses MT1-MMP production and proMMP-2 activation in human fibrosarcoma HT-1080 cells and thereby inhibits tumor invasion (metastasis), using Invasion Chamber coated with collagen (tumor invasion assay in vitro). Additionally, we have a cooperative study with this team about anti-angiogenic action of hyperthermia by suppressing gene expression and production of tumour-derived vascular endothelial growth factor in vivo and in vitro ${ }^{18)}$.

It is of great interest to elucidate mechanisms of metastasis suppression, taking our new theory into 
Thermal Med, 26 [4] : 109-119, 2010.

consideration. In 1866, German physician, Dr. Busch published a case report in which malignant tumor was spontaneously cured luckily for one patient with malignant tumor by fever, and this patient was found to have sarcoma (collagen-rich interstitial tumor), supporting validity of this theory.

\section{Conclusion}

In cancer patients with metastasis, serum level of MMP-1 was increased by 2-fold as compared to healthy individuals, whereas serum level of TIMP-2 (a protein that suppresses all MMPs activity), was decreased. MMP-1 activity was then assessed by MMP-1/TIMP-2 ratio, and this ratio was increased approximately by 3-fold in cancer patients with metastasis, compared to healthy individuals. In addition, MMP-1 activity was normalized in WBH-responders primarily as a result of decreased MMP-1 levels in serum, indicating that serum level of MMP-1 is a useful indicator for assessment of the efficacy of WBH. At the same time, MMP-1 activity is a predictor for inhibitory effect of this therapy on tumor metastasis. Nowadays, it has said that MMP inhibitor gives us side effects. But we extremely expect the natural treatment that MMP is inhibited by heat.

\section{References}

1) Deryugina E.I., Luo G.X., Reisfeld R.A., Bourdon M.A., Strongin A.: Tumor cell invasion through matrigel is regulated by activated matrix metalloproteinase-2. Anticancer Res, 17: 3201-3210, 1997.

2) Mehta P.B., Jenkins B.L., McCarthy L., Thilak L., Robson C.N., Neal D.E., Leung H.Y. : MEK5 overexpression is associated with metastatic prostate cancer, and stimulates proliferation, MMP-9 expression and invasion. Oncogene, 22 : 1381-1389, 2003.

3) Robins H.I., Dennis W.H., Neville A.J., Shecterle L.M., Martin P.A., Grossman J., Davis T.E., Neville S.R., Gillis W.K., Rusy B.F. : A nontoxic system for 41.8 degrees C whole-body hyperthermia : results of a Phase I study using a radiant heat device. Cancer Res, 45 : 3937-3944, 1985.

4) Holmgran L., O’Reilly M.S., Folkman J. : Dormancy of micrometastases : Balanced proliferation and apotosis in the presence of angiogenesis suppression. Nat Med, 1: 149-153, 1995.

5) Ueno H., Nakamura H., Inoue M., Imai K., Noguchi M., Sato H., Seiki M., Okada Y.: Expression and tissue lacalization of mambrane-types 1,2, and 3 matrix metalloproteinases in human invasive breast carcinomas. Cancer Res, 57 : 2055-2060, 1997.

6) Elnemr A., Yonemura Y., Bandou E., Kinoshita K., Kawamura T., Takahashi S., Tochiori S., Endou Y., Sasaki T. : Expression of collagenase-3 (matrix metalloproteinase-13) in human gastric cancer. Gastric Cancer, 6: 30-38, 2003.

7) Murray G.I., Duncan M.E., O’Neil P., Melvin W.T., Fothergill J.E. : Matrix metalloproteinase-1 is associated with poor prognosis in colorectal cancer. Nat Med, 2: 461-462, 1996.

8) Zucker S., Lysik R.M., Zarrabi M.H., Moll U. : M (r) 92,000 type IV collagenase is increased in plasma of patients with colon cancer and breast cancer. Cancer Res, 53 : 140-146, 1993.

9) Grigioni W.F., D’Errico A., Fortunato C., Fiorentino M., Mancini A.M., Stetler-Stevenson W.G., Sobel M.E., Liotta L.A., Onisto M., Garbisa S. : Progression of gastric carcinoma revealed by interactions between tumor cells and basement membrane. Mod Pathol, 7 : 220-225, 1994.

10) Takeuchi T., Takeuchi A., Chikuma S., Kobayashi Y., Kashiwagi S., Hasumura M., Yokoyama M.: Clinical experiences of far-infrared whole body hyperthermia by the use fo RHD2002. Jpn J Hyperthermic Oncol, 12: 156-161, 1996. (Japanese)

11) Yokoyama T., Yamamoto M., Shima K., Suzuki K., Sako C., Ito G., Kume M., Maeda M. : Clinical usefulness of serum 
pyridinoline cross-linked carboxyterminal telopeptide of type I collagen for diagnosis of bone metastases in patients with primary lung cancer. Respirology, 10 : 300-304, 2005.

12) Hayashi T., Curran-Patel S., Prockop D.J.: Thermal stability of the triple helix of type i procollagen and collagen. Precautions for minimizing ultravilolet damage to proteins during circular dichroism studies. Biochemistry, 18-19: 4182-4187, 1979.

13) Peltonen L., Palotie A., Hayashi T., Prockop D.J.: Thermal stability of type I and type III procollagens from normal human fibroblasts and from a patient with osteogenesis imperfecta. Proc Natl Acad Sci USA, 77 : 162-166, 1980.

14) Matsuda H., Strebel F.R., Kaneko T., Danhauser L.L., Jenkins G.N., Toyota N., Bull J.M. : Long duration-mild whole body hyperthermia of up to 12 hours in rats: feasibility, and efficacy on primary tumour and axillary lymph node metastases of a mammary adenocarcinoma : implications for adjuvant therapy. Int J Hyperthermia, 13 : 89-98, 1997.

15) Toyota N., Strebel F.R., Stephens L.C., Matsuda H., Oshiro T., Jenkins G.N., Bull J.M.: Therapeutic efficacy and apoptosis and necrosis kinetics of doxorubicin compared with cisplatin, combined with whole body hyperthermia in a rat mammary adenocarcinoma. Int J Cancer, 76: 499-505, 1988.

16) Toyota N., Strebel F.R., Stephens L.C., Matsuda H., Bull J.M. : Long-duration, mild whole body hyperthermia with cisplatin : tumour response and kinetics of apotosis and necrosis in a metastatic rat mammary adenocarcinoma. Int $\mathbf{J}$ Hyperthermia, 13 : 497-506, 1997.

17) Sato T., Sawaji N., Matsui N., Sato H., Seiki M., Mori Y., Ito A.: Heat shock suppresses membrane type 1-matrix metalloproteinase production and progelatinase A activation in human fibrosarcoma HT-1080 cells and thereby inhibits cellular invasion. Biochem Biophys Res Commun, 265 : 189-193, 1999.

18) Sawaji Y., Sato T., Takeuchi A., Hirata M., Ito A.: Anti-angiogenic action of hyperthermia by suppressing gene expression and production of tumour-derived vascular endothelial growth factor in vivo and in vitro. Br J Cancer, 86 : 1597-1603, 2002. 